\title{
LAVH or TAH - choosing it wise and making it safe
}

\section{K. P. Muralikrishnan Nambiar, K. Supriya*, Suchithra Thunga, Simar Kaur, Joel Karunakaran}

\begin{abstract}
Department of Obstetrics and Gynecology, Kasturba Medical College, Manipal University, Mangalore, Karnataka 575001, India
\end{abstract}

Received: 06 December 2015

Revised: 29 January 2016

Accepted: 08 February 2016

\author{
*Correspondence: \\ Dr. K. Supriya, \\ E-mail: dr_ksupriya@yahoo.com
}

Copyright: (C) the author(s), publisher and licensee Medip Academy. This is an open-access article distributed under the terms of the Creative Commons Attribution Non-Commercial License, which permits unrestricted non-commercial use, distribution, and reproduction in any medium, provided the original work is properly cited.

\begin{abstract}
Background: Hysterectomy is the most commonly performed surgery in our gynaecological practice, abdominal route being the most common. Here we compare the various features and outcomes of laparoscopically assisted vaginal hysterectomy (LAVH) with total abdominal hysterectomy (TAH).

Methods: The study design is a retrospective observational study. Outcome measures were indication, duration, complications of surgery, post op recovery and cost following TAH and LAVH.

Results: A total of 116 cases underwent hysterectomy. Of these 98 underwent TAH and 18 underwent LAVH. Commonest indication for TAH in our study was fibroid followed by abnormal uterine bleeding (AUB); whereas in LAVH it was AUB followed by fibroid. Mean operating time in TAH was 118 minutes whereas in LAVH it was 166 minutes. One patient who underwent LAVH had ureteric injury and another had vault abscess. There were no major complications among TAH cases. A few patients had minor complications like fever, wound infection and urinary tract infection following TAH whereas fever was the only minor complication seen in a minority of the LAVH patients. Mean fall in haemoglobin in TAH was $1.05 \mathrm{gm} \%$ whereas in LAVH it was $0.95 \mathrm{gm} \%$. None of the patients required postoperative blood transfusion. A few patients following TAH required additional analgesics apart from routine whereas in LAVH none required it. Mean duration of hospital stay following TAH was 6.84 days where as in LAVH it was 3.1 days. Mean hospital expenses in TAH were INR 28480, while for LAVH it was 44360.

Conclusions: Undoubtedly expertise is the decisive factor behind the success of hysterectomy. LAVH though advantageous in many aspects like less post operative pain and cosmetic benefits, it could be technically demanding with availability only in well-equipped centres and cost factors. Surgeons need to be trained in all modalities of hysterectomy.
\end{abstract}

Keywords: Laparoscopically assisted vaginal hysterectomy (LAVH), Total abdominal hysterectomy (TAH), Duration, Complication, Cost

\section{INTRODUCTION}

Hysterectomy is one of the most commonly performed surgical procedures in our gynaecological practice. $33 \%$ of women undergoes hysterectomy by the age of $60 .{ }^{1}$ Over the last 10 years, approximately 6.5 million hysterectomies were done all over the world, of which $70 \%$ were by the abdominal approach ${ }^{1}$. Nevertheless vaginal hysterectomy should be the preferred mode of hysterectomy whenever feasible. ${ }^{2}$ Laparoscopically assisted vaginal hysterectomy (LAVH) as suggested by Reich and decaprio combines the benefits of abdominal and vaginal hysterectomy. It is predicted that in near future LAVH may replace total abdominal hysterectomy (TAH) ${ }^{3}$ In this study, we compared the patient selection, indication, complications and duration of hospital stay following laparoscopically assisted vaginal hysterectomy 
(LAVH) with total abdominal hysterectomy (TAH) performed by the same team of gynaecologists.

\section{METHODS}

The study design is a retrospective observational study performed at a tertiary care centre. We included the patients who underwent abdominal hysterectomy and LAVH at the study setting under the same team of gynecologist between September 2013 to August 2015. All patients who were operated for malignancy were excluded. Various parameters like age, parity, history of previous surgeries, indication for surgery, uterine size, associated comorbidities, various complications associated with the surgery like blood loss, injury to adjacent structures, wound complications, fever, Vault infection, $\mathrm{Hb}$ level $24 \mathrm{hrs}$ after operation, length of hospital stay were assessed. Data was analysed using SPSS version 17 and test of significance employed is students unpaired t test.

\section{RESULTS}

A total of 116 cases underwent hysterectomy between September 2013 and August 2015 under the team of gynaecologist at a tertiary care centre. Of these 98 underwent TAH and 18 underwent LAVH. The dempgraphic characters of the patients were matching (Table 1). Mean age of the patients who underwent LAVH was 45.2 and TAH was 46.2 years. The most common comorbidity among the patients was diabetes mellius followed by hypertension. All patients had BMI in the normal range of 19 to 25.

Table 1: Demography.

\begin{tabular}{|llll|}
\hline \multirow{2}{*}{ Patient parameter } & $\begin{array}{l}\text { TAH, } \\
\text { n }(\%)\end{array}$ & $\begin{array}{l}\text { LA VH, } \\
\text { n }(\%)\end{array}$ \\
\hline Mean age in years & 46.2 & 45.2 \\
\hline \multirow{2}{*}{ Parity } & Nullipara & $1(5.5)$ & $12(12.2)$ \\
\cline { 2 - 4 } & Parous & $17(94)$ & $86(88.2)$ \\
\hline \multirow{4}{*}{ Comorbidity } & Diabetes & $20(20.4)$ & $4(22)$ \\
\cline { 2 - 4 } & Hypertension & $8(8.2)$ & $1(5.5)$ \\
\cline { 2 - 4 } & Anemia & $2(2)$ & NIL \\
\cline { 2 - 4 } & $\begin{array}{l}\text { Thyroid } \\
\text { disorders }\end{array}$ & $9(9.1)$ & $1(5.5)$ \\
\cline { 2 - 4 } & RHD & $1(1)$ & NIL \\
\hline Previous abdominal surgery & $18(18.3)$ & NIL \\
\hline \multirow{3}{*}{ BMI } & $\begin{array}{l}\text { Normal } \\
\text { range (19 } \\
\text { to 25) }\end{array}$ & $\begin{array}{l}\text { Normal } \\
\text { range }(19 \\
\text { to 25) }\end{array}$ \\
\hline
\end{tabular}

Most common indication (Table 2) for TAH in our study was fibroid followed by abnormal uterine bleeding (AUB); whereas in LAVH it was AUB followed by fibroid. Majority of the LAVH cases had normal uterine size whereas most TAH cases had uterine size of 12 weeks or more. Surgical outcomes (Table 3) were as follows. Mean operating time in TAH was 118 minutes whereas in LAVH it was 166 minutes. One patient who underwent LAVH had ureteric injury and another had vault abscess. There were no major complications among TAH cases. A few patients had minor complications like fever, wound infection and urinary tract infection following $\mathrm{TAH}$ whereas fever was the only minor complication seen in a minority of the LAVH patients. Mean fall in haemoglobin in TAH was $1.05 \mathrm{gm} \%$ whereas in LAVH it was $0.95 \mathrm{gm} \%$. None of the patients required postoperative blood transfusion. A few patients following TAH required additional analgesics apart from routine whereas in LAVH none required it. Mean duration of hospital stay following TAH was 6.84 days where as in LAVH it was 3.1 days. Mean hospital expenses in TAH were INR 28480, while for LAVH it was 44360.

Table 2: Indications for surgery.

\begin{tabular}{|c|c|c|c|}
\hline & & $\begin{array}{l}\text { TAH; } \\
\text { n (\%) }\end{array}$ & $\begin{array}{l}\text { LAVH; } \\
\text { n }(\%)\end{array}$ \\
\hline \multirow{5}{*}{ Indication } & Fibroid & $80(81.6)$ & $6(33.3)$ \\
\hline & DUB & $10(10.2)$ & $10(55.5)$ \\
\hline & Adenomyosis & $2(2)$ & NIL \\
\hline & Endometriosis & $6(6.1)$ & $1(5.5)$ \\
\hline & $\begin{array}{l}\text { Adnexal } \\
\text { pathology }\end{array}$ & $1(1)$ & NIL \\
\hline \multirow{3}{*}{$\begin{array}{l}\text { Mean } \\
\text { uterine } \\
\text { size }\end{array}$} & 8 weeks or less & $25(25)$ & $11(61.1)$ \\
\hline & 10 weeks & $15(15.3)$ & $7(38.8)$ \\
\hline & $\begin{array}{l}\text { More than } 12 \\
\text { weeks }\end{array}$ & $58(59.18)$ & NIL \\
\hline
\end{tabular}

Table 3: Surgical outcomes.

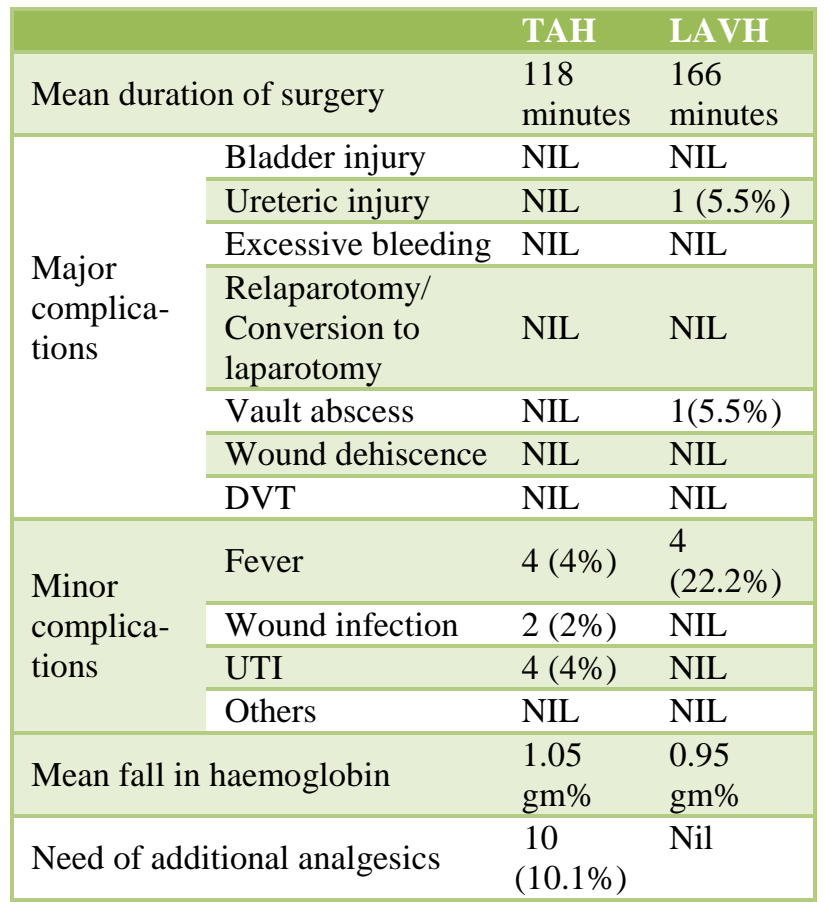




\section{DISCUSSION}

TAH is the most common gynaecological procedure performed in India. ${ }^{6}$ The numbers have increased over the past decade. This procedure involves abdominal access following a liberal abdominal incision. For the same reason which is very much influenced by a cosmetic concern, LAVH has become very popular and a commonly sought after surgery these days. In LAVH, steps of hysterectomy in part or whole is performed laparoscopically and the removal of uterus and vault closure done vaginally. Necessary attempts have been made in this study to weigh the pros and cons of both approaches.

In our study, data of all cases of TAH and LAVH performed by the same team of gynaecologists during the study period was analysed. This reduced the risk of varying surgical skill among the surgeons influencing our data. The patient demography in our study was matching. This made the data analysis more convincing and convenient. The number of patients who had previous abdominal surgery were 18 (18.3\%) in TAH cases and nil in LAVH cases. However this could be due to the selection bias of the surgeon, as, there is a tendency in them to choose cases without previous abdominal surgeries to minimize the risk of injuries due to adhesions and hence conversion from LAVH to TAH. A similar choice in patient selection has been shown in many other similar studies. ${ }^{4}$

The uterine size in TAH cases in our study were mostly more than 12 weeks (58 i.e. 59.8\%) in comparison to LAVH cases. This again is in consensus with the surgeons discretion of choosing the most apt mode of hysterectomy. One of the previous studies has cited large uterine size $(>12 \mathrm{~cm})$ as a reason to perform direct laparotomy and hysterectomy. ${ }^{4}$

Though there are many factors influencing the duration of hysterectomy, the two most important ones are mode of hysterectomy and the expertise of the surgeon. In our study the mean operating time for TAH was 118 minutes and 166 minutes for LAVH. Almost all previous studies have stated the operating time for LAVH is more than $\mathrm{TAH}$, though the time disparity comes down with expertise and also the use of advanced technology such as harmonic scalpels where in cutting and coagulation occurs concurrently. ${ }^{1,4-7}$

Fibroid was the most common indication for TAH followed by abnormal uterine bleeding (AUB), endometriosis, adenomyosis and adnexal pathology. Whereas most LAVH was done in view of AUB, followed by fibroid and endometriosis. This is in consensus with other similar studies and the earliest one on this dating as early as $19944^{1,5-7}$ This shows that the trends in indication for hysterectomy has remained the same over ,the past two decades irrespective of the type of population.
The most important aspect of our study was to analyse the complications that could be associated with TAH and LAVH. In the present study TAH was not associated with any major complication. However we had two major complications following LAVH, where in one had ureteric injury which was detected and managed 6 weeks later and the other had vault abscess which was managed conservatively. This is different from the findings of similar studies, where in the investigators found most of the major complications being associated with TAH.$^{1,4,6,7}$ One of the previous studies had findings similar to ours stating that complications are associated more with LAVH. ${ }^{5}$ It is difficult to conclude on this aspect as the number of cases who, underwent LAVH were less. Further studies with more number of LAVH cases are required on this.

Among the minor complications, fever and urinary tract infection were common. Most of this fever was seen in LAVH patients following general anaesthesia and could be a manifestation of upper respiratory tract infection following intubation. Urinary tract infection following TAH could be due to prolonged catheterisation. This is subsidised by the fact that there was no UTI following LAVH. Study by J.D. Our study is in agreement with study by Arbogast, et al and many others have documented UTI after TAH at more or less the same incidence. ${ }^{1}$ Two patients had wound infection following TAH. This again is a complication exclusive to TAH as there were no wound infections following LAVH. Sudhev Sutasanasuang, et al and J.D. Arbogast documented almost equal incidence of wound infection in LAVH an TAH cases. ${ }^{1,5}$ But most other studies have stated that wound infection following LAVH is nil. Similar to the other studies we compared with, our study too showed that none of the patients following LAVH needed additional analgesics. Whereas $10.1 \%$ (10) patients following TAH required additional analgesics. ${ }^{5}$

Average fall in haemoglobin concentration was 1.05 $\mathrm{gm} \%$ in TAH group and $0.95 \mathrm{gm} \%$ in LAVH group which was comparable. Though this skeletal difference is not significant, it is a finding contrary to many of the contemporary studies like the one by Zahra Asgari, et al and could be due to the expertise of our gynaecologist in performing LAVH. ${ }^{6}$ This is also subsidised by the fact that none of the LAVH had to be converted to TAH.

Mean hospital stay was more in TAH (6.84 days) as compared to LAVH (3.1 days). All the other studies ${ }^{1,3-7}$ showed a similar duration of stay following TAH and LAVH. All the observations in our study suggest the surgical modality being chosen largely based on surgeons' and patients' choice. Similar studies done before have suggested the same. ${ }^{9}$ Cost of LAVH was more than TAH in our study. This is mainly due to the sophisticated instruments and consumables that is largely used in LAVH compared to TAH. Most other studies observed a similar cost pattern. Nevertheless this bearing 
on cost could be overcome by early return to work after LAVH. ${ }^{10}$

Main drawbacks of our study were less number of cases who underwent $\mathrm{LAVH}$ and retrospective nature of the study.

There was no conflict of interest in this study.

\section{CONCLUSIONS}

Undoubtedly expertise is the decisive factor behind the success of hysterectomy like in any other surgery. But careful patient selection for different modality of hysterectomy is the key in performing a complication free surgery. LAVH though advantageous in many aspects like less post op pain and cosmetic benefits, it could be technically demanding with availability only in wellequipped centres and cost factors. With increasing awareness among patients regarding LAVH, surgeons need to be trained in all modalities of hysterectomy.

Funding: No funding sources

Conflict of interest: None declared

Ethical approval: The study was approved by the Institutional Ethics Committee

\section{REFERENCES}

1. Arbogast JD, Welch RA, Riza ED, Ricaurte EL, Pieper DR. Laparoscopically assisted vaginal hysterectomy appears to be an alternative to total abdominal hysterectomy journal of laparoendoscopic surgery. 1994;4(3).

2. Lake AG, McPencow AM. Surgical site infection after hysterectomy. Am J Obstet Gynecol. 2013;209(5).

3. Busacca M, Zupi E, Garcea N, Paparella P, Catalano GF. Laparoscopically assisted vaginal hysterectomy versus total abdominal hysterectomy: A prospective, randomized, multicenter study. American Journal of Obstetrics and gynecology. 1999;180(2):270-5.
4. Devaja O, Samara I, Papadopoulos AJ. Laparoscopically Assisted Vaginal Hysterectomy (LAVH) Versus Total Abdominal Hysterectomy (TAH) in Endometrial Carcinoma Prospective Cohort Study. International Journal of Gynecological Cancer. 2010;20(4).

5. Sutasanasuang S. Laparoscopic Hysterectomy versus Total Abdominal Hysterectomy: A Retrospective Comparative Study. J Med Assoc Thai. 2011;94(1).

6. Jyotsana, Manhas K. Clinical Trial of Laparoscopically Assisted Vaginal Hysterectomy Versus Total Abdominal Hysterectomy. JK Science, Journal of Medical Education \& Research. 2006;8(2):97-100.

7. Asgari Z, Bahreini F, Samiee H, Eslami B, Tehranian A, Sabet S. Comparison of laparoscopically assisted vaginal hysterectomy and total abdominal hysterectomy. Medical Journal of the Islamic Republic of Iran. 2008;22(1):22-8.

8. Tsai EM, Chen HS, Long CY, Yang CH, Hsu SC, $\mathrm{Wu} \mathrm{CH}$, et al. Laparoscopically Assisted Vaginal Hysterectomy versus Total Abdominal Hysterectomy: A Study of 100 Cases on LightEndorsed Transvaginal Section. Gynecol Obstet Invest. 2003;55:105-9.

9. Harris JA, Rone BK. Postoperative Morbidity of Minimally Invasive Hysterectomy Approach and Uterine Size. Journal of Clinical Gynecology and Obstetrics. 2015;4(1):153-9.

10. Jahan S, Das T, Mahmud N, Khan MI, Akter L, Mondol SK, et al. A comparative study between laparoscopically assisted vaginal hysterectomy and vaginal hysterectomy: Experience in a tertiary diabetes care hospital in Bangladesh. J Gynecol Endosc Surg. 2011;2(2):79-84.

Cite this article as: Nambiar KPM, Supriya K, Thunga S, Kaur S, Karunakaran J. LAVH or TAH choosing it wise and making it safe. Int J Reprod Contracept Obstet Gynecol 2016;5:659-62. 